\title{
An Adaptive Multilevel Feedback based Learning Management Framework on Cloud Environment
}

\section{U. Udhayakumar, G.Murugaboopathi}

\begin{abstract}
Internet becomes the key source of communication to engage with everyone and everywhere around the world at any time. The advent of internet provides enormous way to transform an existing system into digital form. The impact of this adoption reflected back in all the domains, notably in healthcare, education, communication and so on. Information and Communication Technology (ICT) is a collective term, represents the components and infrastructure that enables the modern day computing. Cloud Computing is an essential part of ICT that delivers the computing services and resources based on demand and availability. It provides flexibility to the stakeholders to scale their resources virtually. All these technologies make the activities of day-to-day life easier and comfortable. E-Learning becomes an emerging concept that inherits the functionalities of modern day computing approaches. To makes the learner more engaging and interactive with the courses, new frameworks are developed online. With the help of cloud platform, delivering education-related services becomes handy. In this paper, a new concept is introduced with a thematic framework in theoretical aspects to improve the way to deliver personalized recommendations to the user based on the feedback provided on each course enrolled by the learner. This system helps the learners to select a course that is more relevant to their domain. Moreover, this feedback system helps the instructor of the course to improve their standard by providing some suggestions based on the learners comments. This system could be beneficial for both the learner as well as the instructor by providing personalized recommendations
\end{abstract}

Keywords: Cloud Computing, E-Learning, Feedback System, Learning Management System, Natural Language Processing.

\section{INTRODUCTION}

Education is a basic and important need of every individual as a part in their lifetime. Access to learning becomes a key factor that decides the delivery of educational content to everyone. To make education accessible to all, transformation of learning system from traditional methods to digital system is significantly important [1]. E-Learning becomes a prominent way and an optimal solution to providing access to everyone; improve the quality of education and its standards [2]. The adoption of technology in learning community replaces traditional teaching strategies by transforming them into e-learning systems. It

Revised Manuscript Received on December 05, 2019

U.Udhayakumar, Scholar, Department of Computer Science, Bharathiar University, Coimbatore. udhayakumar.msc@gmail.com

G.Murugaboopathi, Associate Professor, Department of Computer Science and Engineering, Kalasalingam Academy of Research and Education, Tamilnadu. gmurugaboopathi@gmail.com provides more flexibility to learners to virtually connect with the participants and instructor via internet rather than being physically present in classrooms. Information and Communication Technology (ICT) enables the access to information through technology and electronic devices anywhere. It binds the people through integrating digital gadgets with the help of wireless communication medium [3]. It reaches a wide range of learner's community by providing ease-of-access to the educational contents.

Cloud computing is a sophisticated technology, delivers various services such as data storage, infrastructure, software etc. through internet as a medium of communication. The services can be accessed through web portals through client login system. Based on the stakeholder's demand, the resources are allocated. It can also be scaled later whenever it is required [4]. It is highly flexible in cloud environment to customize the utilities based upon the needs. Installation and deployment of physical devices are properly made by the service providers. The main role of the consumer is to estimate the required resource with respect to the cost. Cloud supports virtualization, so the data can be stored in virtual hardware, makes it more secure and ensures the integrity [5].

Learning Management System is a kind of software that facilitates course owners to create new courses, updating documents related to the course, managing the participants, conducting online exams and so on. This software can be hosted into a physical server as well as in cloud environment. As a trend and benefit, e-learning systems are migrated to cloud from traditional hosting services [6]. A majority of difference can be observed in both the scenarios. Hosting a course in web server needs more knowledge about the process involved in it. But in cloud, all the systems are well configured, so that it can be directly hosted without the intervention of client in handling physical devices [7]. Moreover, cloud offers more support on hosting services and guidelines to make the process more simple and effective. In any point of view, cloud-based LMS stands one step ahead of other traditional based LMS and has high level of significance in client community.

The rest of the paper is organized as follows. Section 2 briefs the works related to this system. In section 3, concept of e-learning is described. Learning Management System and its types are discussed in section 4 . An in-depth analysis is provided in section 5 on Cloud Computing. 
Section 6 highlights the significance of deploying LMS in cloud. In section 7, the proposed methodology is projected conceptually and section 8 concludes the work.

\section{BACKGROUND STUDY}

A new environment is proposed in this work namely, Microlearning as a Service (MLaaS). It provides virtual cloud-based learning environment in order to satisfy the demands met with the clients. To achieve more personalized approach in this system, education data mining concepts are widely adopted to make this Massive Open Online Course (MOOC) more reachable to the participants [8]. To introduce this cloud-based e-learning system in higher education, a preliminary architecture with all components is represented as stack. Many solutions are proposed to enhance the system to increase scaling factors, resource sharing and utilization strategies [9].

An interactive cloud-based e-learning and training system is proposed [10] to connect the trainers and learners in an effective way together. Quality of Service (QoS), resource utilization and content delivery are the main objectives focused in this work to improve the performance of e-training system. Effect of security systems in cloud environment on e-learning systems is an important factor. It influences in the integrity and robustness of the system [11].

A comprehensive analysis has been made on e-learning systems to evaluate the acceptance factor on academic community. Many factors are included while considering the mode of evaluation of input from the responders [12]. Prediction of adaptability rate of transforming traditional learning system into digital services through e-learning and LMS is evaluated using Fuzzy based analytical and hierarchical processes. Structural modeling through equation analysis and

techniques are applied to examine the collaborative learning system affected by adoption [13].

Improving the quality in education field can be done through e-learning [14]. This can be further enhanced through Educational Data Mining (EDM) approaches on extracting hidden patterns through intelligent approaches. A Personalized content delivery on e-learning system to provide optimal recommendations on selecting courses of their opinion is done through evolutionary strategies [15]. Compatible Genetic Algorithm is a new methodology proposed to find optimal methods to improve the system.

A Standard guideline to scale the resources on cloud-based laboratory systems for e-learning process is suggested on sophisticated learning platforms [16]. To make MOOC courses more accessible and covering wider area of exposure, a new combinational algorithm is suggested with a personalized recommendation methods [17]. Sentiment analysis in e-learning system might provide better suggestions on course selection procedures. In this method, a fuzzy-based approach is developed to capture the emotion from the learner response $[18,19]$.

Ontology-based recommendation system is developed with multiple stages each performs categorization, analysis and knowledge representation in separate phases [20]. A smart learning system using artificial intelligence is deployed through learning style determination on e-learning [21]. A cloud service delivery model is proposed in view of supporting web 4.0 to make it more generic to be accessed by any modern devices [22].

\section{E-LEARNING}

E-Learning is an effective way of providing the learning strategy with the help of sophisticated communication technologies. The main barrier between the learner and the instructor can be highlighted as lack of communication or proper interaction [23]. In traditional classroom-based learning system, the physical presence of learner and instructor is inevitable. In such a way, many drawbacks are identified in traditional learning systems. To sort out the problem of such cases, e-learning becomes the prominent solution.

\section{CLOUD COMPUTING}

Cloud Computing, simply referred as "Cloud" is an emerging technology and becomes the paradigm shift that enables the delivery of computing resources on-demand basis to the stakeholders according to their requirements. It might be anything from an application to even a data center [25]. These services can be delivered and accessed through internet as the mode of communication. The success of cloud lies in its nature of adaptability and flexibility.

\section{CLOUD-BASED LMS}

Cloud-based Learning Management System provides high level of flexibility to the course owners. The course can be hosted into cloud environment. It can be accessed through internet by logging into the site of service providers. The lengthy procedure followed in traditional LMS to host a course in server is avoided here [26]. In this framework, the course management software needs not to be installed. Rather, it exhibits some guidelines to upload the courses materials, creating new content related to different courses, conducting exams, quiz and interaction with the hosting authorities. The content can be accessed by anyone who has the permission.

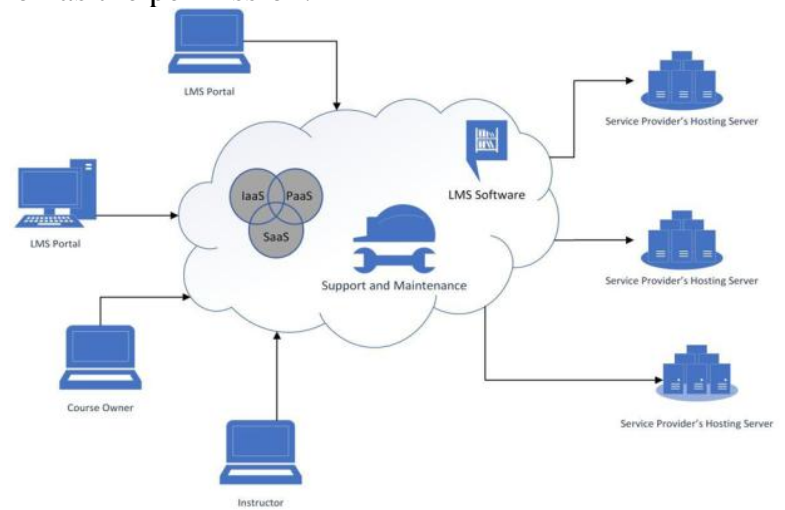

Fig 4: Architecture of Cloud-based LMS

Published By:

Blue Eyes Intelligence Engineering 
This authentication and access control mechanisms can be managed securely by hosting service providers. In all the cases, the course owner doesn "et have to keep their hands busy with setting up the system. It is completely customized with respect to their requirements. Whenever the system lags out of service, it can be instantly boosted up by scaling up the required resources. The following are the advantages of the cloud-based LMS

$\begin{array}{ll}\text { - } & \text { Enhanced Accessibility } \\ \text { - } & \text { Customization } \\ \text { - } & \text { Data Security } \\ \text { - } & \text { Easier Maintenance } \\ & \text { Rapid Deployment }\end{array}$

Table 1: Comparison of Cloud based LMS with Hosted LMS

\section{MULTILEVEL FEEDBACK BASED LMS}

In this system, a new layer is added up into the existing architecture that promotes more usability and user experience on cloud-based e-learning platform[31]. Most of the online courses have feedback facility to extract the thoughts of the learner about the course and the efficiency of the instructor. In general it can be classified into two types. One category is described as queries. The learner can share their suggestions through comments. In other way, ratings can be given. This rating system follows scaling system, where it usually lies in the range of $1-5$. This rating and comment data plays a vital role in deciding the course standard and quality of the content delivery. Natural Language Processing is an exciting field, deals with processing human linguistics to transform them into meaningful insights into a computer understandable way. To provide more personalized relevant course recommendations to the learner, applying NLP techniques on past comments and ratings of the course becomes more reasonable and effective. Optimal suggestions are given to the instructor to improvise themselves by undergoing self-retrospection based on learner"es comments. Also, from the opinions of the participants, it supports to append more recently updated concepts on learning objective to make the course technically sounder.

\begin{tabular}{|l|l|}
\hline \multicolumn{1}{|c|}{ Cloud-based LMS } & \multicolumn{1}{c|}{ Hosted LMS } \\
\hline $\begin{array}{l}\text { Expenses are more } \\
\text { affordable }\end{array}$ & $\begin{array}{l}\text { Subjected to change based } \\
\text { on the requirements }\end{array}$ \\
\hline $\begin{array}{l}\text { Most of the functionalities } \\
\text { are automated }\end{array}$ & $\begin{array}{l}\text { Manual Configuration } \\
\text { process }\end{array}$ \\
\hline $\begin{array}{l}\text { No prior knowledge or } \\
\text { expertise needed }\end{array}$ & $\begin{array}{l}\text { Needs some expertise } \\
\text { guidelines }\end{array}$ \\
\hline $\begin{array}{l}\text { Highly scalable with less } \\
\text { effort }\end{array}$ & $\begin{array}{l}\text { Scaling is comparatively } \\
\text { complex }\end{array}$ \\
\hline $\begin{array}{l}\text { Features and functionalities } \\
\text { are customizable }\end{array}$ & $\begin{array}{l}\text { Less customization with } \\
\text { restrictions }\end{array}$ \\
\hline Easy to maintain & Maintenance is difficult \\
\hline
\end{tabular}

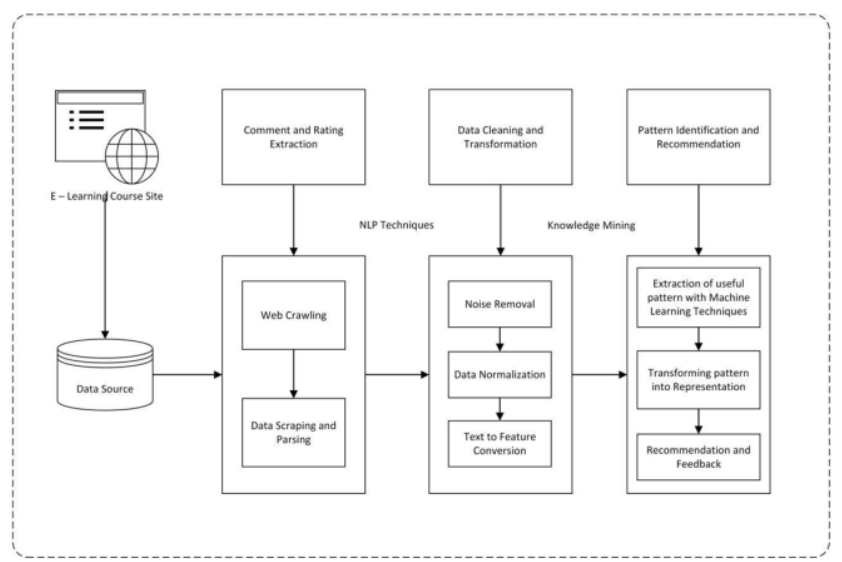

Fig 5: Schematic representation of proposed method

\section{Natural Language Processing}

NLP is a branch of study related to computer field, integrated with computational linguistics, artificial intelligence and human language recognition systems. The core functionality of NLP is to analyze and process large amount of data collected from human linguistic patterns to transform them into computer understandable way [27]. Also, mining of knowledge pattern from these data to identify the behavioral structure of individuals becomes more active. Some instances are said to be recommender systems, sentiment analysis etc. [28]. Types of data involved in NLP processing are commonly referred to be text, speech, images and videos.

\section{NLP Techniques: \\ Web Mining}

This concept generally follows data mining strategies to discover hidden knowledge and pattern from online content, otherwise World Wide Web.

\section{Scraping}

This is a process of extracting useful and relevant content from various web sources through some tools or libraries. The extracted information is then stored in a structured database or in a table, otherwise a spreadsheet.

\section{Parsing}

Dividing the extracted content into little piece of chunks to make it as a hierarchical form to make the analysis easier and exhibits the relationship between the keywords.

\section{Web crawling}

A structured way of indexing the web contents through some patterns or algorithms through an automated script.

\section{Text Pre-processing}

Pre-processing is an inevitable methodology that makes data free from hassle. Presence of noise, inconsistent and redundant information will be eliminated by applying some robust techniques [29]. The processed data can be further taken into consideration as the input for the next procedure. 


\section{Noise Removal}

Elimination of noisy content present in the scraped data can be done through various noise removal techniques. Some of them are stop words, URL and punctuation removal, normalization and standardization.

\section{Data Normalization}

\section{Lemmatization}

Mapping and analysis of morphological words and maintains proper usage of vocabulary in a sentence or statement. It also identifies the root form of a word.

\section{Stemming}

It is the process of stripping the suffixes from a word.

\section{Text to Feature Transformation}

Once the data is normalized, it should be converted to features for further processing. The following techniques are mostly used to perform the transformation.

\section{Syntactical Parsing}

a. Dependency trees

In each sentence, the words are framed together in a meaningful way. Based on the dependency grammar, the relationship between the words present in a sentence can be identified.

\section{b. Part of Speech}

Part of Speech otherwise (PoS) is a tagging method. The tags might be a noun, verb, adverb, adjectives etc.), which has some meaningful relationship associated with the words in a sentence. PoS tagging is mostly used in Word Sense Ambiguition (WSA), stop word removal, lemmatization and stemming processes.

\section{Entity Extraction}

In a sentence, entity represents the chunk of statements, words namely verb and noun phrases. This process will be used in chatbots, recommendation systems and so on.

\section{a. Topic Modeling}

It is the concept of identifying the topic of a corpus by mining the hidden information from it in an unsupervised way [30].

\section{b. Named Entity Recognition}

Detection of entities such as name, place, materials etc. are called as NER.

\section{c. $\quad \mathbf{N}$-Grams}

Combination of more than a word together is called as N-Gram. For example "Hello World" is said to be bi-gram. Single word is represented as unigram.

\section{Statistical Features}

\section{a. Term Frequency-Inverse Document} Frequency (TF-IDF)

TF-IDF is a method to convert the text information into vectors. It can be done by identifying the occurrence of words in a document[32].

\section{b. Word/Sentence Count}

Summing up the frequency of a specific word and occurrence of key terms is called a word count.

\section{Workflow of the proposed NLP scheme Benefits of the proposed work}

This system is more beneficial to the learner as well as the instructor. The following points depict the importance of the system by highlighting its benefits.

1. Personalized course recommendation to the learner. (Topic Modeling)

2. Improvement of course structure based on the feedback. (TF-IDF)

3. Rating the performance of the instructor to enhance the standard and quality of delivering content. (Word Count)

\section{CONCLUSION}

This paper presents a comprehensive framework of cloud-based e-learning system powered with adaptive feedback mechanism. In general, the learner is responsible to find out the courses that are more relevant to their expectation. But in some cases, they might end up with selecting a course, not matching their criterion. To sort out these issues, the system proposed in this work introduces a new layer that provides precise suggestions to the learner. This could be achieved by applying some NLP techniques to extract more sensitive content out from the past user comments and the ratings of the course. Also, this system provides suggestions to the instructor, which might improve the standard of the course and way of delivering the content in later sessions. The components of the course followed by its structure are adaptive and subjective to change with respect to the learneres suggestion. On the whole, this framework is completely developed in a way such that it could transform and adapt itself based on the feedback provided by the learners. Not all, but optimal suggestions can be further taken into consideration for updating the system. This framework can be enhanced by introducing more standards and techniques to automate the process of identifying optimal suggestions to make the contents more personalized and accurate to everyone.

\section{REFERENCES}

1. Collins, A., \& Halverson, R. (2018). Rethinking education in the age of technology: The digital revolution and schooling in America. Teachers College Press.

2. Vrielink, R. O., Jansen, E. A., Hans, E. W., \& van Hillegersberg, J (2019). Practices in timetabling in higher education institutions: systematic review. Annals of operations research, 275(1), 145-160.

3. Kumar, R., Sachan, A., Mukherjee, A., \& Kumar, R. (2018). Factors influencing e-government adoption in India: a qualitative approach. Digital Policy, Regulation and Governance, 20(5), 413-433.

4. Rittinghouse, J. W., \& Ransome, J. F. (2016). Cloud computing. implementation, management, and security. CRC press.

5. Ali, M., Khan, S. U., \& Vasilakos, A. V. (2015). Security in cloud computing: Opportunities and challenges. Information sciences, 305, 357-383

6. Stephenson, J. (Ed.). (2020). Teaching \& learning online: new pedagogies for new technologies. Routledge. 
7. Caulfield, A. M., Chung, E. S., Putnam, A., Angepat, H., Fowers, J., Haselman, M., ... \& Lo, D. (2016, October). A cloud-scale acceleration architecture. In The 49th Annual IEEE/ACM International Symposium on Microarchitecture (p. 7). IEEE Press.

8. Sun, G., Cui, T., Yong, J., Shen, J., \& Chen, S. (2018). MLaaS: a cloud-based system for delivering adaptive micro learning in mobile MOOC learning. IEEE Transactions on Services Computing, 11(2), 292-305.

9. El Mhouti, A., Erradi, M., \& Nasseh, A. (2018, October). Application of Cloud Computing in E-learning: A Basic Architecture of Cloud-Based E-learning Systems for Higher Education. In The Proceedings of the Third International Conference on Smart City Applications (pp. 319-333). Springer, Cham.

10. Samra, H. E., Li, A. S., Soh, B., \& AlZain, M. A. (2019). A Cloud-Based Architecture for Interactive E-Training. In Cloud Security: Concepts, Methodologies, Tools, and Applications(pp. 1379-1392). IGI Global.

11. El-Sofany, H. F., El-Seoud, S. A., \& Farouk, R. T. H. (2018, September). Studying the Effect of Using E-Learning Through Secure Cloud Computing Systems. In International Conference on Interactive Collaborative Learning (pp. 54-63). Springer, Cham.

12. Bouchrika, I., Harrati, N., Mahfouf, Z., \& Gasmallah, N. (2018). Evaluating the acceptance of e-learning systems via subjective and objective data analysis. In Software data engineering for network elearning environments (pp. 199-219). Springer, Cham.

13. Yadegaridehkordi, E., Nasir, M. H. N. B. M., Noor, N. F. B. M., Shuib, L., \& Badie, N. (2018). Predicting the adoption of cloud-based technology using fuzzy analytic hierarchy process and structural equation modelling approaches. Applied Soft Computing, 66, 77-89.

14. Sheshasaayee, A., \& Bee, M. N. (2018). E-learning: Mode to Improve the Quality of Educational System. In Smart Computing and Informatics (pp. 559-566). Springer, Singapore.

15. Christudas, B. C. L., Kirubakaran, E., \& Thangaiah, P. R. J. (2018). An evolutionary approach for personalization of content delivery in e-learning systems based on learner behavior forcing compatibility of learning materials. Telematics and Informatics, 35(3), 520-533.

16. Hossain, Z., Bumbacher, E., Brauneis, A., Diaz, M., Saltarelli, A. Blikstein, P., \& Riedel-Kruse, I. H. (2018). Design guidelines and empirical case study for scaling authentic inquiry-based science learning via open online courses and interactive biology cloud labs. International Journal of Artificial Intelligence in Education, 28(4), 478-507.

17. Xiao, J., Wang, M., Jiang, B., \& Li, J. (2018). A personalized recommendation system with combinational algorithm for online learning. Journal of Ambient Intelligence and Humanized Computing, 9(3), 667-677.

18. Karyotis, C., Doctor, F., Iqbal, R., James, A., \& Chang, V. (2018). A fuzzy computational model of emotion for cloud based sentiment analysis. Information Sciences, 433, 448-463.

19. Appalla, P., Selvaraj, R., Kuthadi, V. M., \& Marwala, T. (2018). Hybrid Fuzzy Recommendation System for Enhanced E-learning. In Advances in Systems, Control and Automation(pp. 21-32). Springer, Singapore.

20. Tarus, J. K., Niu, Z., \& Mustafa, G. (2018). Knowledge-based recommendation: a review of ontology-based recommender systems for e-learning. Artificial intelligence review, 50(1), 21-48.

21. Bajaj, R., \& Sharma, V. (2018). Smart Education with artificial intelligence based determination of learning styles. Procedia computer science, $132,834-842$.

22. Alghamdi, F. A. (2018). An Integrated Cloud model for intelligent E-Learning system. International Journal of Applied Engineering Research, 13(14), 11484-11490.

23. Tawfik, A. A., Reeves, T. D., Stich, A. E., Gill, A., Hong, C., McDade, J., ... \& Giabbanelli, P. J. (2017). The nature and level of learner-learner interaction in a chemistry massive open online course (MOOC). Journal of Computing in Higher Education, 29(3), 411-431.

24. Koskay, K., Perreault, S., Black, S. J., Denlinger, T., \& Poirier, G. (2017). U.S. Patent No. 9,704,129. Washington, DC: U.S. Patent and Trademark Office.

25. Petrolo, R., Loscri, V., \& Mitton, N. (2017). Towards a smart city based on cloud of things, a survey on the smart city vision and paradigms. Transactions on Emerging Telecommunications Technologies, 28(1), e2931.

26. González-Martínez, J. A., Bote-Lorenzo, M. L., Gómez-Sánchez, E., \& Cano-Parra, R. (2015). Cloud computing and education: A state-of-the-art survey. Computers \& Education, 80, 132-151.

27. Amato, F., Cozzolino, G., Moscato, V., \& Moscato, F. (2019). Analyse digital forensic evidences through a semantic-based methodology and NLP techniques. Future Generation Computer Systems.

28. Hao, Q., Galyardt, A., Barnes, B., Branch, R. M., \& Wright, E. (2018). Automatic Identification of Ineffective Online Student Questions in Computing Education. arXiv preprint arXiv:1807.07173.
29. Karthik, S., Perumal, R. S., \& Mouli, P. C. (2018). Breast Cancer Classification Using Deep Neural Networks. In Knowledge Computing and Its Applications (pp. 227-241). Springer, Singapore.

30. Karami, A., Gangopadhyay, A., Zhou, B., \& Kharrazi, H. (2018). Fuzzy approach topic discovery in health and medical corpora. International Journal of Fuzzy Systems, 20(4), 1334-1345.

31. R. K. Devi, G. Murugaboopathi and P. Vijayakumar, "A Graph-Based Mathematical Model for an Efficient Load Balancing and Fault Tolerance in Cloud Computing," 2017 Second International Conference on Recent Trends and Challenges in Computational Models (ICRTCCM) Tindivanam, 2017, pp. 136-140.

32. R. K. Devi and G. Murugaboopathi, "A graph and connected dominating set-based mathematical model for task mapping in cloud computing," 2016 International Conference on Information Communication and Embedded Systems (ICICES), Chennai, 2016, pp. $1-6$.

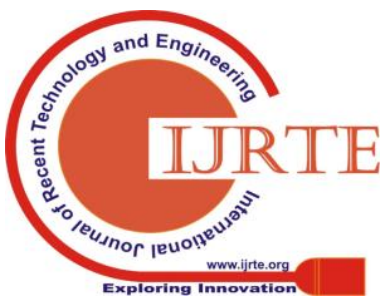

